\title{
Environmental impacts on coastal structures with a case evaluation of armor stone protection at Keweenaw Waterway, USA
}

\author{
M. Zakikhani ${ }^{1}$, D. W. Harrelson ${ }^{1}$, J. G. Tom, J. A. Kissane ${ }^{2}$, \\ M. K. Allis ${ }^{3}$ \& J. E. Kolber ${ }^{4}$ \\ ${ }^{I}$ The U.S. Army Engineer Research and Development Center, USA \\ ${ }^{2}$ U.S. Army Corps of Engineers, Chicago District, USA \\ ${ }^{3}$ U.S. Army Corps of Engineers, Detroit District, USA \\ ${ }^{4}$ U.S. Army Corps of Engineers, Buffalo District, USA
}

\begin{abstract}
The evaluation of armor stone performance as a viable construction material is essential to increasing the longevity of maritime structures used to protect harbors, coastal areas and navigable waterways from damaging waves and other forces. The environmental parameters have led to the armor stones deteriorating faster than laboratory testing indicates. This paper provides an overview of the decomposition of the four rock types (limestone, granite, quartzite, and concrete) over the five field inspections. The meteorological variables were used to calculate the number of freeze-thaw events that occurred over the time period. The water wave height data were used to calculate stone deterioration from wave actions. The results from the field observations, together with the meteorological analysis, were used to help better parameterize the numerical model and assist in identifying problems in scalability from laboratory test samples to field samples.

Keywords: hydrodynamic forces, response of structures, fluid dynamics, armor stone durability, great lakes, numerical modeling, laboratory testing.
\end{abstract}

\section{Introduction}

Degradation of armor stone placed in coastal navigation areas in the United States Great Lakes has occurred as the result of a number of interacting and interrelated natural factors, such as seasonal weather changes, and repeated 
cycles of temperature (e.g., flowing water, wetting and drying, wave action, freeze and thaw, etc.). This study was proposed to evaluate the importance of various factors in armor stone durability, consider the relevance of test procedures and possibly develop scaling factors and test methods that will be more representative of the materials used. It also provides guidelines for the personnel involved in source selection activities, so they may be more consistent across the organization. The research provides a better understanding of the relationship between the standard tests used in stone specifications and the performance of stone in the structures. Several investigations have developed standard field and laboratory procedures for careful comparisons of stone of similar, if not identical, properties. Previous investigations have been directed at considering the causes, based on comparison of different types of stone used in different structures. Much of the testing performed on stone submitted as material for erosion protection is based on the protocols used to evaluate concrete aggregate and sub-grade stone materials - that is, tests designed for use on material orders of magnitude smaller than armor stone of several tons. Acceptance of sources is then based on a combination of test results, performance records, and quarry inspections.

As a secondary objective, beyond evaluating testing, the results of this study and the previous work on armor stone durability would be used to develop guidelines for future armor stone selection procedures with respect to ranking of stone types, excavation methods and geologic characteristics of the materials available within a region. These guidelines could also be considered when developing documents, such as "Engineering Considerations during Construction", for use in evaluating proposed sources.

Three sites, Burns Harbor, Cleveland Harbor and Keweenaw Waterway were selected for evaluation of armor stone performance. Index stones were placed in the structures and monitored over the study period. Samples from quarries used in shoreline projects were designated and tested using existing ASTM or testing protocols contained in existing stone specifications that stipulate the size of samples. These test results were compared to tests of larger size samples to consider the effects of scale. In addition, larger samples were placed in structures so that they may be subjected to the conditions that cause weathering of armor stone and the results of their performance have been compared to the laboratory results. To consider the combined effects of environmental stresses on armor stone, testing were done to evaluate the performance of stone subjected to both freezing and thawing and wetting and drying. This testing was performed on the same samples rather than independently, as is more typically done. The combined testing realistically simulates the environmental conditions in the structure. In addition, by including stone of different rock types (i.e. igneous, metamorphic and sedimentary), the relative scaling effects can be evaluated to determine whether the scaling factors, if they exist, are constant or variable by rock type. After evaluating monitoring data, a determination was made as to the relative comparability of scaled laboratory test results and material durability in coastal projects in the Great Lakes, and recommendations made as to the appropriate laboratory tests for future stone specifications. 

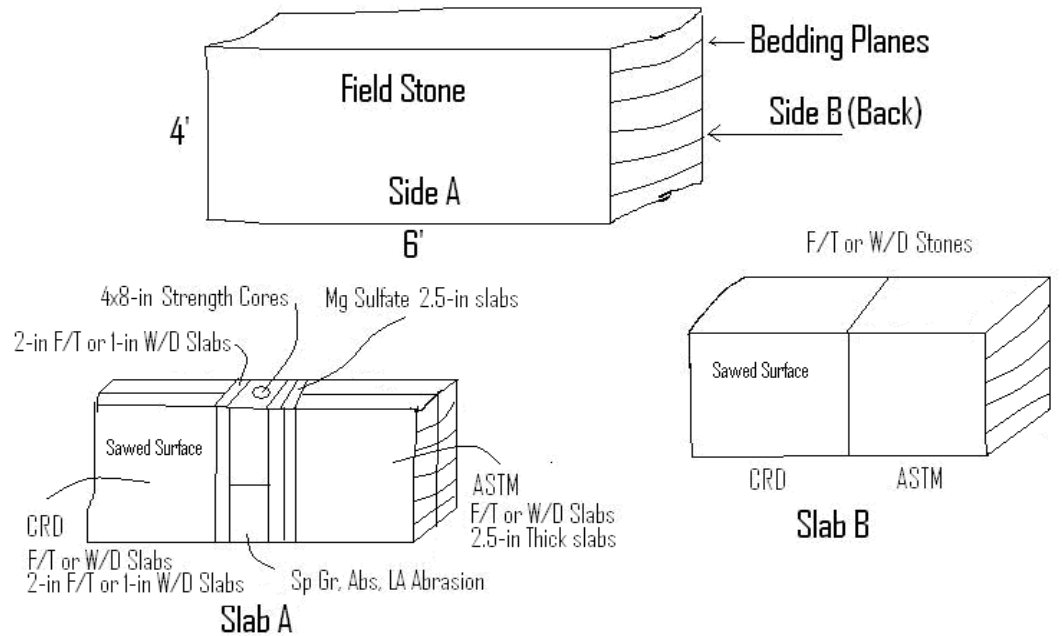

Figure 1: Drawing of the cutting lines and test specimens.

\section{Field sampling and monitoring}

To determine qualified samples for this study, several quarry sites that have historically supplied material for shoreline protection in and around the Great Lakes Region were visited. The five samples received represent two of five material types proposed for the entire investigation. Samples identified as MCNP 1, 2, 3 are stone discard pieces from stones placed in the field for monitoring from the Hayton Quarry. Each sample consisted of two slabs, each approximately $4-\mathrm{ft}$ by $6-\mathrm{ft}$ by $1-\mathrm{ft}$, from the original stone and was assigned Concrete and Materials Branch Serial No. 070103, 070104, and 070105, respectively. The smaller, thinner slabs are further identified as Slab A and the larger thicker, more massive slabs are further identified as Slab B (fig. 1). Samples identified as MCNP 4 and 5 are also discard pieces from stones placed in the field from Valders Quarry. These samples also consisted of two slabs, each approximately $4-\mathrm{ft}$ by $6-\mathrm{ft}$ by $1-\mathrm{ft}$, and was assigned CMB Serial No. 070106 and 070107 , respectively. The samples proposed for Phase I of this investigation are the CMB Serial No. 070104 (MCNP-2) and 070105 (MCNP-3).

\section{Numerical modeling}

\subsection{Estimation of degradation rate}

Latham [1] provided a simple approach to estimate reduction in armor rock weights as results of several environmental and other impacts. Factors affecting the degradation rate are the intrinsic material properties of the rock source, the 
production-influenced geometric properties of the armors tine, the environmental boundary conditions at the coastal site, and the armor layer design concepts used. The parameters affecting stone degradation rates are provided in table 1 .

Table 1: $\quad$ Degradation-rate factors for armor stone (post-construction).

\begin{tabular}{|c|c|c|c|c|}
\hline Type of factor & Controlling factor & & & Parameter \\
\hline \multirow{4}{*}{$\begin{array}{l}\text { Intrinsic } \\
\text { material } \\
\text { properties of } \\
\text { the rock }\end{array}$} & Mineralogy & \multirow[t]{3}{*}{$\begin{array}{l}\text { Rock } \\
\text { fabric } \\
\text { strength }\end{array}$} & $\begin{array}{l}\text { Resistance } \\
\text { to } \\
\text { weathering }\end{array}$ & $\begin{array}{ll}K_{s} & (\text { see } \\
\left.X_{6}\right) & \end{array}$ \\
\hline & Micro-texture & & abrasion & $K_{s}$ \\
\hline & Weathering grade & & $\begin{array}{l}\text { Type-II } \\
\text { impact } \\
\text { breakage }\end{array}$ & $\begin{array}{l}K_{s}(\text { see } \\
\left.X_{4}\right)\end{array}$ \\
\hline & Block integrity & $\begin{array}{l}\text { Block } \\
\text { strength } \\
\text { due to } \\
\text { existence } \\
\text { of macro- } \\
\text { flaws }\end{array}$ & $\begin{array}{l}\text { Type-I } \\
\text { impact } \\
\text { breakage }\end{array}$ & $\left(\right.$ see $\left.X_{4}\right)$ \\
\hline \multirow{3}{*}{$\begin{array}{l}\text { Production } \\
\text { influenced } \\
\text { geometric } \\
\text { properties }\end{array}$} & Block size $\left(\mathrm{W}_{50}\right)$ & & & $X_{1}$ \\
\hline & $\begin{array}{l}\text { Block grading } \\
\left(\mathrm{W}_{85} / \mathrm{W}_{15}\right)\end{array}$ & & & $X_{2}$ \\
\hline & Initial shape $\left(\mathrm{P}_{\mathrm{R}}\right)$ & & & $X_{3}$ \\
\hline \multirow[t]{4}{*}{$\begin{array}{l}\text { Environmental } \\
\text { boundary } \\
\text { conditions }\end{array}$} & $\begin{array}{l}\text { Incident wave } \\
\text { energy }\left(\mathrm{e} . \mathrm{g} \cdot \mathrm{H}_{\mathrm{S}} \mathrm{T}^{2}{ }_{\mathrm{m}}\right. \\
\left.\text { or } \mathrm{H}_{\mathrm{s}}\right)\end{array}$ & & & $X_{4}$ \\
\hline & zone of structure & & & $X_{5}$ \\
\hline & $\begin{array}{l}\text { Meteorological } \\
\text { effects }\end{array}$ & & & $X_{6}$ \\
\hline & $\begin{array}{l}\text { Water-borne } \\
\text { attrition agents }\end{array}$ & & & $X_{7}$ \\
\hline \multirow{2}{*}{$\begin{array}{l}\text { Factors } \\
\text { influenced by } \\
\text { design of } \\
\text { armor layer }\end{array}$} & $\begin{array}{l}\text { Concentration of } \\
\text { wave attack (slope } \\
\text { angle+ tidal range) }\end{array}$ & & & $X_{8}$ \\
\hline & $\begin{array}{l}\text { Armor stone } \\
\text { mobility in design } \\
\text { concept (e.g. Hs/ } \Delta \\
D_{\text {n } 50} \text { ) }\end{array}$ & & & $X_{9}$ \\
\hline \multicolumn{5}{|c|}{$\begin{array}{l}\mathrm{W}_{50} \text { is the median weight of blocks. } \mathrm{W}_{85} \text { and } \mathrm{W}_{15} \text { are the } 85 \text { and } 15 \text { percent } \\
\text { lighter by weight values. PR is the Fourier Asperity Roughness parameter. HS } \\
\text { and Tm are the significant (i.e. average of the highest one third waves) wave } \\
\text { height and mean wave period. } \Delta \text { is the buoyant density of rock relative to sea } \\
\text { water and } \mathrm{D}_{n 50} \text { is the nominal size of } \mathrm{W}_{50} \text { block. }\end{array}$} \\
\hline \multicolumn{5}{|c|}{ Source: Latham [1] } \\
\hline
\end{tabular}


To determine degradation rate for a given armor stone, a sample of the material is tested in an abrasion mill simulation of the wear process. This provides a graph of weight versus laboratory time. Laboratory time is converted to years on site using an equivalent wear time factor, which is derived from a product of nine weighted parameters (see table 1). The effects of fracturing and spalling as well as abrasion are included.

\subsubsection{Example of degradation model}

The rock samples are used in the abrasion mill to create plot of fractional weight loss versus revolutions (fig. 2). This graph gives the typical loss in asperity roughness observed in milling tests. The equivalent wear time factor, $X$ is calculated as product of all ratings.

$$
X=\prod_{l}^{9} X_{i}
$$

The value $X$ is then used to convert number of years in service to thousands of revolutions in mill. Using fig. 1 and the number of revolutions, $W / W_{0}(W=$ final stone weight; $W_{0}=$ initial stone weight) will be estimated and finally the reduction in weight will be calculated.

As an example input parameters for two site situations are given in table 2 (Latham [1]): (i) for a 3 ton, basalt in tropical climate, medium grading, dynamic design, and (ii) for 4.5 ton, temperate climate, narrow grading, static design.

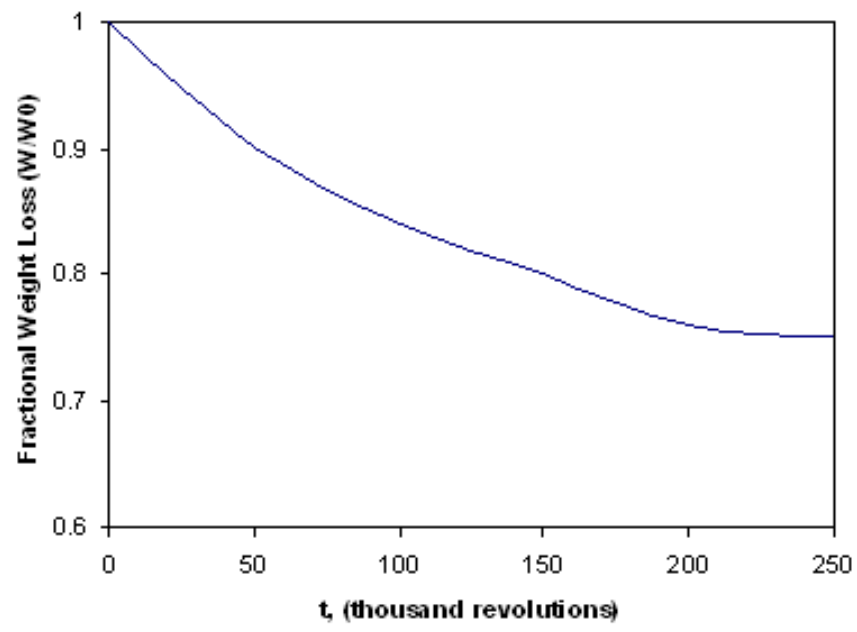

Figure 2: Abrasion mill test results for a specific type of armor stone. 
Table 2: $\quad$ Example site situation summary.

\begin{tabular}{|l|l|l|l|}
\hline \multicolumn{2}{|l|}{} & Ratings & \\
\hline Parameter & (i) & (ii) \\
\hline$X_{1}$ & size & 0.72 & 0.84 \\
\hline$X_{2}$ & grading & 1.0 & 1.2 \\
\hline$X_{3}$ & shape & 1.5 & 1.5 \\
\hline$X_{4}$ & wave energy & 2.0 & 2.0 \\
\hline$X_{5}$ & zone & 1.0 & 1.0 \\
\hline$X_{6}$ & climate & 0.2 & 1.0 \\
\hline$X_{7}$ & attrition & 1.0 & 1.0 \\
\hline$X_{8}$ & concentration of attack & 1.5 & 1.0 \\
\hline$X_{9}$ & block mobility & 1.0 & 2.0 \\
\hline$X$ & & 0.6 & 6.0 \\
\hline
\end{tabular}

\subsection{Characterization of rock heterogeneity}

Liu et al. [2] describes a statistical approach (homogeneity index) to characterize the heterogeneity in rock. According to this article, the Weibull distribution (Weibull [3]; Hudson [4]) describes very well the experimental data for the distribution of microstructures within rock. Therefore, the Weibull statistical distribution is used to characterize the rock heterogeneity. The Weibull distribution may be simplified as:

$$
\mathrm{Q}(\sigma)=\int_{0}^{\sigma} \mathrm{P}(\mathrm{x}) \mathrm{dx}=1-\exp \left[-\left(\frac{\sigma}{\sigma_{0}}\right)^{\mathrm{m}}\right]
$$

where $Q$ is a simplified form of Weibull distribution, $\sigma$ is the elemental parameter $(\mathrm{MPa}), \mathrm{P}$ is the Weibull probability density function, $\mathrm{m}$ is the shape parameter describing the scatter of $\sigma$ and describes the heterogeneity of rock, and $\sigma_{0}$ is the mean value of the physical-mechanical parameters of the specimen (elemental parameter).

The most recommended method for calculating the homogeneous index $\mathrm{m}$ (Curtis and Juszczyk [5]; Davies [6]) is to rank strength $(\sigma)$ data from smallest to largest and the assignment of respective $Q(\sigma)$ values according to the following:

$$
\mathrm{Q}(\sigma)=\frac{\mathrm{i}}{\mathrm{N}+1}
$$

Where $\mathrm{i}$ is the rank and $\mathrm{N}$ is the total number of specimens. According to Equation 3, the Weibull distribution can be liberalized into the following form:

$$
y=\ln \left[\ln \left(\frac{1}{1-Q(\sigma)}\right)\right]=m \ln \sigma-m \ln \sigma_{0}=A x+B
$$


where $y=\ln [\ln \{1 /[1-\mathrm{Q}(\sigma)]\}], \mathrm{A}=\mathrm{m}, \mathrm{x}=\ln \sigma$, and $\mathrm{B}=-\mathrm{m} \ln \sigma_{0}$. With reference to this equation, a plot of $\ln \sigma$ against $\ln [\ln \{1 /[1-\mathrm{Q}(\sigma)]\}]$ gives the linerelationship and the slope of the line is the homogeneous index m. The best estimate of the homogeneous m may be obtained using the linear least squares (LLS) techniques (Davies [6]):

$$
\mathrm{m}=\mathrm{A}=\frac{\mathrm{n} \sum \mathrm{xy}-\sum \mathrm{x} \sum \mathrm{y}}{\mathrm{n} \sum \mathrm{x}^{2}-\left(\sum \mathrm{x}\right)^{2}}
$$

where $\sum, \mathrm{x}$ and $\mathrm{y}$ in the equations are abbreviations for $\sum_{\mathrm{i}=1}^{\mathrm{n}}, \mathrm{x}_{\mathrm{i}}$ and $\mathrm{y}_{\mathrm{i}}$, respectively.

One of the attractive aspects of the Weibull distribution is the presence of the shape parameter, which allows this function to take a wide variety of shapes. For $\mathrm{m}=1$; this distribution is exponential; at about $\mathrm{m}=1.5$; the distribution is nearly log-normal; and at about $\mathrm{m}=4$, it closely approximates a normal distribution. Since the shape parameter $m$ is a measure of the element parameter variability, it can be considered as a homogeneity index. The larger the index $\mathrm{m}$ is, the more homogeneous is the rock. When $\mathrm{m}$ tends to infinity, the variance tends to zero and an ideal homogeneous rock is obtained.

\subsection{Estimation of freeze-thaw intensity}

The intensity of freezing and thawing depends on the freezing temperature, the duration of the freezing cycle, the available moisture, the slope direction (geographic area properties), degree of saturation, and permeability (rock properties) (Lienhart [7]). The first four of these parameters depend on geographic area and the last two factors are merely rock properties. Linehart [7] describes the calculation of some terms that can be used to calculate intensity and frequency of freeze-thaw cycles.

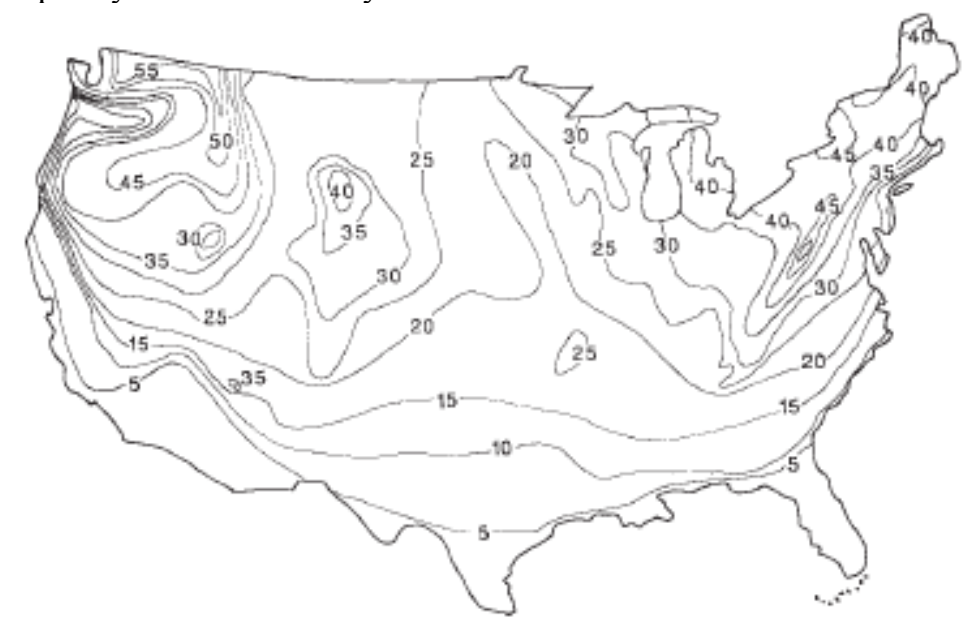

Figure 3: Isoline map of the moist freeze-thaw index for the United States. 
The National Oceanic and Atmospheric Administration (NOAA) climate data are used to calculate mean number of freezing cycle days for each month. These monthly freezing cycle days could then be added to find the mean number of freezing cycle days per year. Since the presence of moisture is significant in the freeze-thaw durability environment it was decided multiply the percent days of precipitation of 0.01 inch or more during the freezing cycle month by mean number of freezing cycle days per year and the product was termed moist freezethaw index. Fig. 3 shows isoline map of the moist freeze-thaw index for the United States using Lienhart method.

\subsection{Design}

The design process for the determination of riprap and armor stone sizes is complex, particularly for the various geometries of channel protection, and is beyond the scope of this article. Various factors must be considered in order to fully understand how the design parameters have an indirect effect on stone performance, and two of the more useful of the design equations will be reviewed to demonstrate the influence of these factors.

Hudson and Fairhurst [8] developed the best known of the design equations for determination of acceptable armor stone size to resist damage from a given wave system based on hydraulic modeling studies. The equation is as follows:

$$
W=H^{3} w_{r} / K_{d}(S r-1) \cot \theta
$$

where $W$ is the weight of the armor unit, $H$ is the average wave height of the highest 10 percent of all waves, $w_{r}$ is the unit mass of the stone, $K_{d}$ is a damage coefficient, $S_{r}$ is the specific gravity of the stone, and $\theta$ is the angle of the slope of the armor stone.

Hudson and Fairhurst [8] present the results of an extensive series of experiments conducted to obtain basic information on the stability, $K_{d}$ of rubblemound breakwaters. These equations along with other design formulations have been used in this study.

\section{Overview of Keweenaw waterway}

The Keweenaw waterway is located on Michigan's Upper Peninsula, USA. The waterway was completed in 1860's. It connects Lake Superior with Portage and Torch Lake. The waterway has been used by shipping companies in the early days to transport copper and other goods. The waterway experiences some of the harshest weather conditions in the great Lakes region with large fluctuations in temperature and high wind and wave action due to large fetch. The local weather has led to stones deteriorating faster than laboratory testing indicates.

Ten index stones were placed within the toe of the western structure: five lime stones, two granites, two quartzites and one cement. The weather data consist of hourly surface observations from Houghton county memorial airport, hourly buoy observations from NOAA buoys and hourly wave data from GLERL GLCFS. 
Freeze-thaw effects have potential to increase rate of deterioration. Water gets into natural and man-made cracks of the stones. When water freezes in these cracks, it causes them to expand, increasing its size and exerting more pressure on surrounding areas. Subsequent thawing leaves larger areas for the process to repeat itself. Two published methods of freeze-thaw cycle techniques were used for this study. The first method is described by Lienhart [7] and the second one is modified form of Arnold et al. [9].

Results of the freeze-thaw cycle calculation indicate that the site observation data are consistent with both methods. Maximum number of freeze-thaw events occur during seasonal changes, such as the late fall and early spring. Most intense period occurred in the winter and month of November. Freeze-thaw cycle had a little correction with the overall rate of the stone degradation.

Waves impacting the structure can cause stone to move around, potentially increasing the rate of deterioration. Hudson and Fairhurst [8] equation is used to determine the minimum weight of a stone to ensure weight of stone to ensure structure stability for a given wave condition. Wave heights had a strong correlation with the degradation of cement.

\section{Summary and conclusion}

The project described here is a multi-year research effort. To date we have completed part of the study. The results presented here are not conclusive. The reader should look for future publications of this research project. Currently, ten index stones have been placed at Keweenaw Waterway and eight index stones at Cleveland Harbor. The Keweenaw samples consist of ten stones, five lime stones, two quartzites, two granites and one cast concrete block. All Keweenaw index stones (except the cast concrete) were cut into roughly rectangular shapes producing a 5-6 ton stone. The concrete block was cast into approximately the same dimensions as the other cut stones. Cleveland Harbor's index stones consist four cut stones; two sandstones and two lime stones and four cast concrete blocks (with varying concrete mixtures). These stones also rectangular in shape average about 9 tonnes in weight. The index stones placed in Keweenaw Waterway and Cleveland Harbor are currently being monitored for rock massloss and degradation. Additionally, specific macroscopic features being monitored include vugs, stylolites and fossils in the limestones and fractures, joints and cracks in the quartzite and granites. Petrographic analysis of various microscopic features is continuing as part of the laboratory efforts.

A total of four rounds of monitoring have been conducted at Keweenaw Waterway. Field observations on these samples indicate that in general the stones are weathering from the edges inward towards the center of the stone. The cast concrete block has shown the most weathering with measurable deterioration and mass-loss beginning along its edges (and some corners) that is progressing towards the center of the stone. This trend is less evident in the other index stones, but four rounds of observations indicate that although stone deterioration and mass-loss is less than for the concrete block, it is still progressing in a similar manner. 
The limestones, quartzites, and granites have had little measurable rock massloss and display no clear trends, but numerous macroscopic features including fractures and joints on all rock types and vugs and stylolites found in the limestones are being monitored for change and a time line for a stone deterioration index is underway.

Several of the Keweenaw index stones displayed ice abrasion during their first winter (2006). This abrasion occurred mainly as scoring of the rock at its waterline due to ice movement. One stone, a quartzite, was moved (displaced to the toe of the structure) during a large storm event in October of 2006, but recovered and replaced on the structure in August 2007.

The field observations and laboratory testing will be used to construct a "stone durability index model" that will be useful in determining the life cycle of large (type A) armor stone. The model will integrate field observations and laboratory testing into a common index that will predict percent rock mass-loss and deterioration rate.

\section{References}

[1] Latham, J-P., Degradation model for rock armour in coastal engineering. Quarterly Journal of Engineering Geology, 24, pp. 101-118, 1991.

[2] Liu, H.Y., Roquete, M., Kou, S.Q. \& Lindqvist, P.-A. , Characterization of rock heterogeneity and numerical verification. Engineering Geology, 72, pp. 89-119, 2004.

[3] Weibull, W., A statistical distribution function of wide applicability. J. Appl. Mech., pp. 293-297, 1951.

[4] Hudson, R. Y., Design of Quarry-Stone Cover Layers for Rubble-Mound Breakwaters, U.S. Army Engineer Waterways Experiment Station Research Report No. 2-2, Vicksburg, MS, 39 p., 1958.

[5] Curtis, R.V. \& Juszczyk, A.S., Analysis of strength data using two- and three-parameter Weibull models. J. Mater. Sci., 33, 1151-1157, 1988.

[6] Davies, I.J., Empirical correction factor for the best estimate of Weibull modulus obtained using linear least square analysis. J. Mater. Sci. Lett., 20, 997-999, 2001.

[7] Lienhart, D.A., The geographic distribution of intensity and frequency of freeze-thaw cycles. Bulletin of the Association of Engineering Geologists, 25(4), pp. 465-469, 1988.

[8] Hudson, J.A., Fairhurst, C., Tensile strength, Weibull's theory and a general statistical approach to rock failure. The Proceedings of the Civil Engineering Materials Conference, Held in Southampton 1969, pp. 901-904, 1969.

[9] Arnold, J. G., Allen, P. M. , Ramanarayanan, T. S. , Srinivasan, R., Muttiah, R. S., The Geographical distribution of freeze/thaw and wet/dry cycles in the United States, Environmental \& Engineering Geoscience, 2(4), pp. 596-603, 1996. 